\title{
Heat Augmentation Using Non-metallic Flow Divider Type Inserts in Forced Convection
}

\author{
D.R. Hase, N.K. Sane, D.V. Ghewade \\ (Department. Of Mechanical Engineering, Walchand College Of Engineering,Sangli, Maharashtra, India)
}

\begin{abstract}
Investigations have been carried out over decades to enhance the heat transfer using active, passive and compound heat augmentation techniques. The present work includes passive heat transfer augmentation technique using non-metallic flow divider type inserts with air as working fluid. Whenever inserts are used for heat transfer enhancement, along with increase in heat transfer rate, the pressure drop also increases. This increase in pressure drop increases the pumping cost. Hence heat augmentation technique should optimize between the benefits of heat transfer rate and increased pressure drop. Initially, for validation of setup, experiments were carried out for plain tube. The results i.e. Nusselt number and friction factor obtained were validated against those obtained from empirical correlation. Secondly, Experimental investigations were carried out using flow divider type non-metallic inserts with varying the Reynolds number and heat input. The nusselt number is increased by $170 \%$ than that for plain tube. Overall Enhancement Efficiency(OEE) for different Reynolds number was above unity.
\end{abstract}

Keywords : Forced Convection, Flow Divider Insert, Heat Augmentation, Nusselt Number, Reynolds Number.

\section{Introduction}

Heat transfer processes in industrial, Automotive and domestic application involves the conversion, transfer and utilization of heat energy. The enhancement of heat transfer in such several application can significantly improves the thermal performance of heat exchange equipments. Heat augmentation techniques are used to increase the convective heat transfer coefficient by increasing the turbulence of the fluid. This technique also leads to increase in pressure drop and consequently the pumping cost. Hence the augmentation technique should optimize between the heat transfer rate and pressure drop. Heat transfer augmentation techniques are broadly classified into three categories:

1) Active techniques,

2) Passive techniques and

3) Compound techniques.

Active methods require some external power input for the improvement of heat transfer and have not shown much prospective owing to intricacy in design. While, Passive methods do not need any external power input and the supplementary power needed to augment the heat transfer is taken from fluid itself, which ultimately leads to drop in fluid pressure. Compound methods are hybrid methods in which both active and passive methods are used in combination. Passive and active techniques that are used for heat augmentation of laminar flow have been discussed in detail by Bargles[1].These are effective but involve complicated design and hence have limited applications [1-3]. Heat augmentation can further increased by perforating the twisted tape with different shapes with different arrangement [3]. These techniques includes twisted tape [3,6]. Use of alternate clockwise and counterclockwise twisted tapes with different twist ratio increases the nusselt number over a range of Reynolds number with uniform flux condition. It leads to superior chaotic mixing [6]. Square cut circular ring [4], coiled tube [5], rough surfaces [8], additives to the fluid [8], extended surfaces [10] have been used successfully to enhance heat transfer.

According to the first technique, insert acts as a turbulence promoter, producing the helical flow of fluid which induces the drive forces to move the heated fluid from boundary surface to core flow. In second technique, by inducing the heat transfer surface area and redevelopment of boundary layer the thermal performance of system is increased. Insertion of twisted tube is the simple passive technique for enhancement of heat transfer coefficient on the tube side of heat exchanger. Although typical twisted tapes offer better heat transfer enhancement, the tapes leads to high pressure drop penalty which limits thermal performance of systems. Therefore, various modified twisted tapes have been designed to reduce pressure loss by introducing spaces or gaps to twisted tapes. Overall enhancement ratio is used to indicate the thermal performance of the enhancement technique over a plain tube with constant pumping power. Dittus-Boelter and Petukhov correlations of forced convection for plain tube were used to validate the setup. 


\section{Experimental Setup}

The photograph of experimental setup is depicted in Fig.1.Experimental setup consists of assembly of channel flow passage including blower, orifice meter, wattmeter, test section, nichrome band heater. The test section is the G.I.pipe with inner diameter of $27.5 \mathrm{~mm}$ and $500 \mathrm{~mm}$ length. Band type nichrome heater is used for heating the pipe (test section). Wattmeter is used to adjust the heater input to the test section. Test section is insulated using asbestos insulation. Two Copper-Constantan (k-type) thermocouple are placed at inlet and outlet section to measure air temperature and 5 thermocouple soldered to the test section. For measuring the pressure head loss across the test section, tapping are provided at inlet and outlet of test section. This head loss is measured using digital manometer. Velocity of air is calculated from the discharge obtained from manometer attached across orifice plate. Control valve is used to adjust the flow rate of air. Before experimentation thermocouples and orifice plate were calibrated.

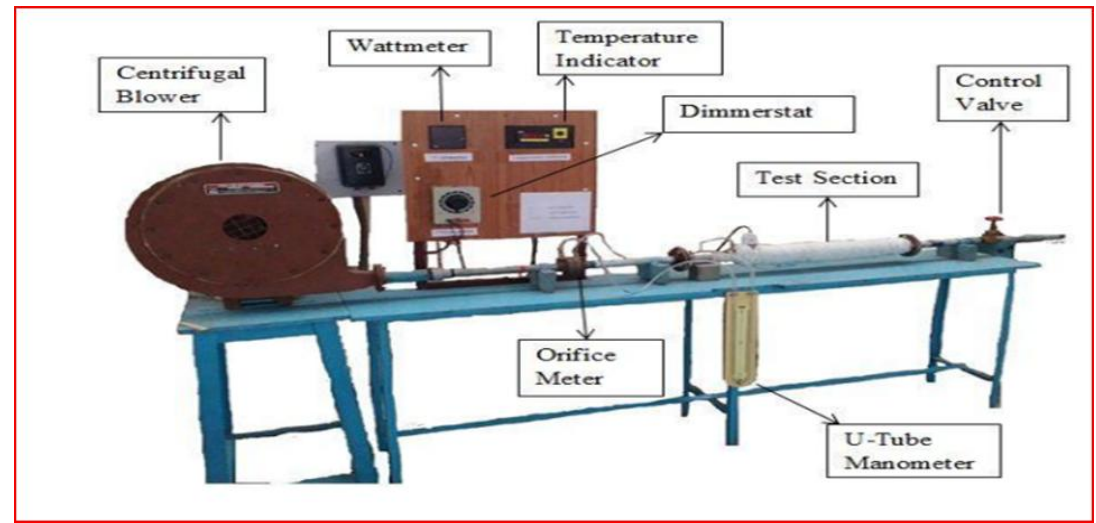

A

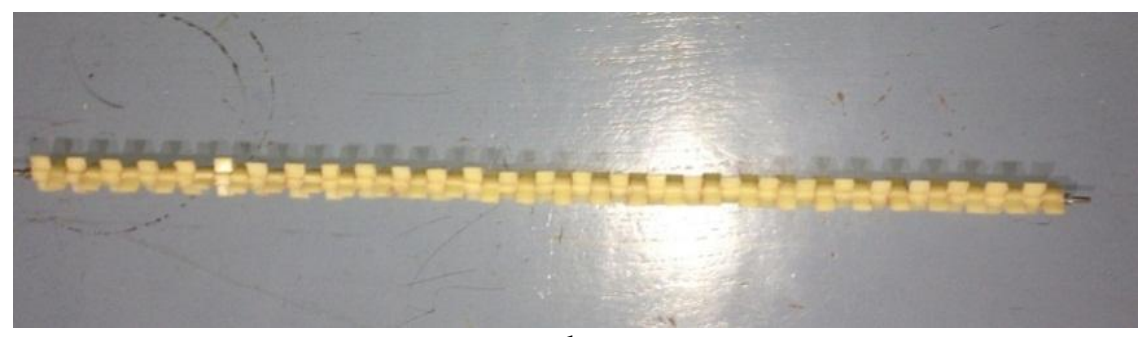

b

Fig.1. a) Photograph of experimental setup b) Nylon flow divider insert

The non-metallic flow divider type insert, which is used as turbulence promoter is depicted in fig. $1 \mathrm{~b}$. Angle between two consecutive blades is kept 90 degree.

\section{Experimental Procedure}

Validation of test set up is done by conducting experiments for known values from Dittus-Boelter and Blasius correlations. Supply is given to the blower motor and the valve is opened slightly. The blower is started and the airflow rate was adjusted by operating the control valve, so that the desired difference in manometer level $(40 \mathrm{~mm}, 80 \mathrm{~mm}, 120 \mathrm{~mm}, 160 \mathrm{~mm}$ or $200 \mathrm{~mm})$ is obtained. Switch on the supply to Nichrome band heater fitted on the test section and give desired voltage input by adjusting the dimmerstat. Thermocouples 2 to 6 are fixed on the test surface to measure surface temperature and thermocouples 1 and 7 are fixed inside the pipe to measure inlet air temperature and outlet air temperature respectively. The readings of the thermocouples are observed every 5 minutes until they show constant values. The variation of tube wall temperatures (T2, T3, T4, T5 and T6) are observed until the constant value is attained and then the outlet air temperature (T7) is measured after it reaches a steady state. The readings of all the seven thermocouples are recorded for three different heater inputs $50 \mathrm{~W}, 75 \mathrm{~W}$ and $100 \mathrm{~W}$ respectively. For each test run, temperatures, volumetric flow rate and pressure drop of bulk air at steady state conditions were noted down. The fluid properties were calculated as the average between the inlet and the outlet temperature. Experiment is carried out at constant heat flux conditions at different mass flow rates. The Reynolds number was varied from 5000 to 17000 during the experimentation. The Nusselt number and the Reynolds number are based on the average tube wall temperatures and the inlet and outlet air temperatures. Nusselt numbers and friction factor calculated from the experimental data for plain tube are compared with the correlations recommended by Dittus-Boelter and Blasius. 
Mean Bulk Temperature,

\section{Equations And Correlations}

$$
\mathrm{T}_{\mathrm{mb}}=\frac{\mathrm{T} 1+\mathrm{T} 7}{2} \quad\left({ }^{\circ} \mathrm{C}\right)
$$

Mean Surface Temperature,

$$
\mathrm{T}_{\mathrm{S}}=\frac{\mathrm{T}_{\mathrm{z}}+\mathrm{T}_{\mathrm{g}}+\mathrm{T}_{4}+\mathrm{T}_{5}+\mathrm{T}_{6}}{2} \quad\left({ }^{\circ} \mathrm{C}\right)
$$

Properties of air, $\mathrm{Cp}, \mu, \mathrm{k}$ and $\operatorname{Pr}$ are calculated at bulk mean temperature i.e. at $\mathrm{T}_{\mathrm{mb} .}$.

Equivalent Column Height of Air,

$$
\mathrm{h}_{\mathrm{a}}=\frac{\mathrm{h}_{w} P_{w}}{P_{a}} \quad(\mathrm{~m})
$$

Volume flow rate

$$
\mathrm{Q}_{\mathrm{d}}=\frac{\mathrm{A} * \mathrm{~A}_{0} * \sqrt{2 * \mathrm{~g} * \mathrm{~h}_{\mathrm{a}}}}{\sqrt{\mathrm{A}^{2} \mathrm{O}_{0}-\mathrm{A}^{2}}} \quad\left(\mathrm{~m}^{3} / \mathrm{s}\right)
$$

Mean Velocity of Air through Pipe

$$
\mathrm{U}=\frac{\mathrm{Q}_{\mathrm{d}}}{\mathrm{A}} \quad(\mathrm{m})
$$

Nusselt number from Dittus-Boelter correlation is given as,

$$
(\mathrm{Nu})_{\mathrm{DB}}=0.023 \times \operatorname{Re}^{0.8} \times \operatorname{Pr}^{0.4}
$$

$$
\text { Where, Reynolds Number }(\mathrm{Re})=\frac{4 * \mathrm{~m}}{\pi * D * \mu}
$$

$$
\text { Prandtl Number }(\operatorname{Pr})=\frac{\mu * C_{p}}{K}
$$

Nusselt number from experimental data can be calculated as,

$$
(\mathrm{Nu})_{\exp }=\frac{\mathrm{h} \times \mathrm{D}_{\mathrm{h}}}{\mathrm{k}}
$$

Where, Convective heat transfer coefficient $(\mathrm{h})=\frac{\mathrm{Q}_{\mathrm{t}}}{\mathrm{A}_{\mathrm{S}} *\left(\mathrm{~T}_{\left.\mathrm{S}-\mathrm{T}_{\mathrm{mb}}\right)}\right.} \quad\left(\mathrm{W} / \mathrm{m}^{2} \mathrm{~K}\right)$

$$
\text { Hydraulic diameter }\left(D_{h}\right)=\frac{4 \times A_{f r}}{\text { wetted perimeter }}
$$

Friction factor Blasius correlation for plain tube,

$$
f=0.316 \times \operatorname{Re}^{-0.25}
$$

Friction factor from petukhov Correlation for plain tube,

$$
f=(0.79 \times \ln \mathrm{Re}-1.64)^{-2}
$$

Friction factor obtained from experimental data can be calculated as,

$$
f=\frac{\Delta p_{\exp }}{\left(\frac{L}{D}\right) x\left(\frac{\rho_{a x} U_{i}^{2}}{2}\right)}
$$

\section{Results And Discussion}

Nusselt number obtained from equation (6) and (9) and friction factor obtained from equation (12), (13) and (14) are compared in order to validate the experimental setup. It is observed that, the experimental data are in 
good agreement with the correlation values, i.e., Dittus - Boelter Correlation and with Blasius correlation as shown in Fig.2

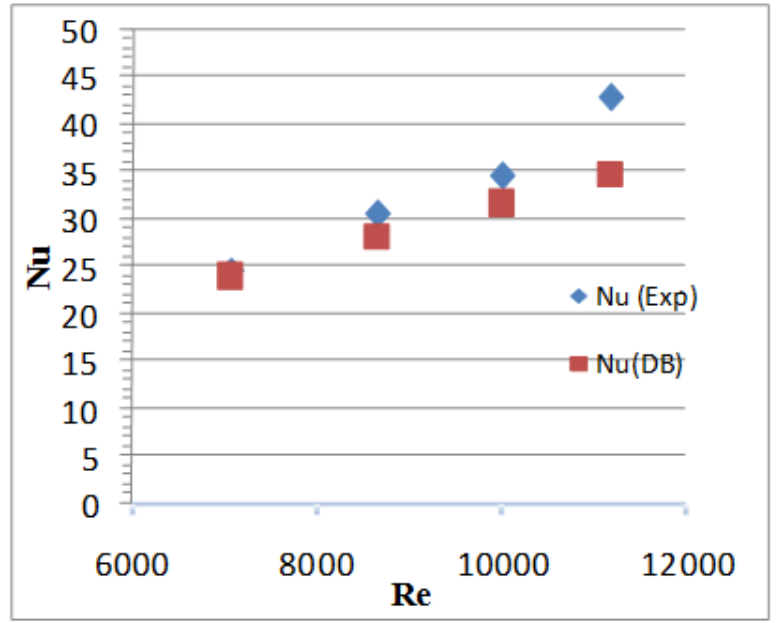

a) For heater input $\mathrm{P}=50$

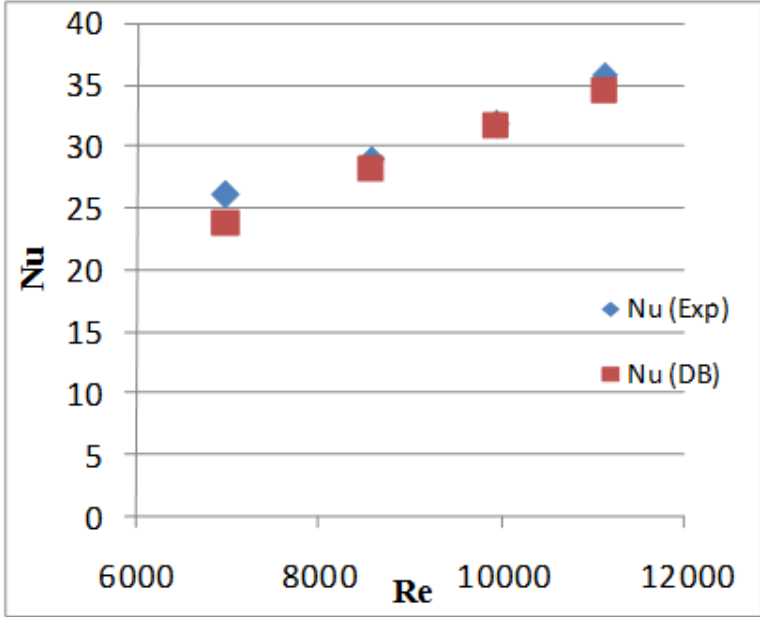

b) For heater input $\mathrm{P}=100 \mathrm{~W}$

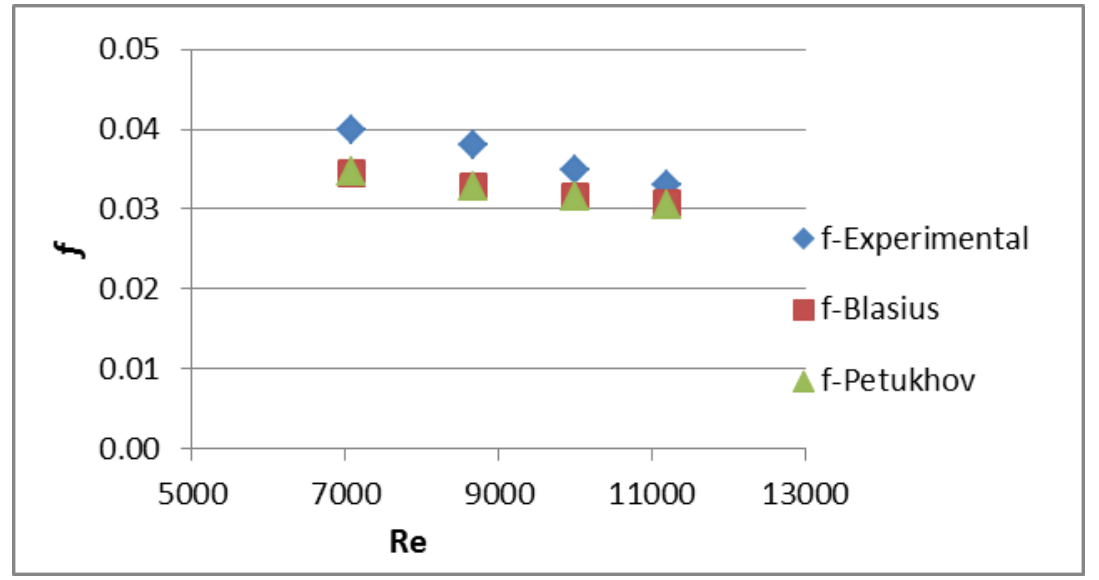

c) Friction factor vs Re

Fig.2. Validation of setup (plain tube)

Experimental investigations were conducted with the flow divider type fiber inserts revealed that, thermal performance of tube fitted with fiber inserts were better than that of plain tube. Results obtained from plain tube and with inserts are as shown in fig.3. Nusselt number and heat transfer coefficient increases for nylon insert. Maximum increase in Nusselt number is $170 \%$ of the plain tube. The friction factor, which is high at lower Reynolds number, tends to reduce with the increase of Reynolds number as shown. This is due to the fact that, $f$ is inversely proportional to square of velocity for a given pipe. So, friction factor is decreases due to increased velocity associated with increase in mass flow rate as shown in fig.4. Overall enhancement ratio and enhancement efficiency are the important terms used to compare the thermal performance of the insert.The Overall Enhancement Rratio(OER) is useful to evaluate the quality of heat transfer enhancement obtained over plain tube at constant pumping power. The value of OER is above unity for different flow rate of air and heater input and maximum value of OER is 1.338 as shown in fig.5.

$$
\eta=\frac{\left[\frac{N u_{i}}{N u}\right]}{\left[\frac{f_{i}}{f}\right]^{\frac{1}{3}}}
$$

Where, $\mathrm{Nu}_{\mathrm{i}}=$ Nusselt number with insert

$\mathrm{f}_{\mathrm{i}}=$ friction factor with insert 
Enhancement efficiency $(\psi)$ indicates thermal performance of heat augmentation technique. Enhancement efficiency is increases with increase in Reynolds number. Maximum value of enhancement efficiency obtained is 2. Fig.4.6 shows the variation of enhancement ratio with Reynolds number.

$$
\Psi=\frac{h_{i}}{h}
$$

Where, $\mathrm{h}_{\mathrm{i}}=$ convective heat transfer coefficient with insert

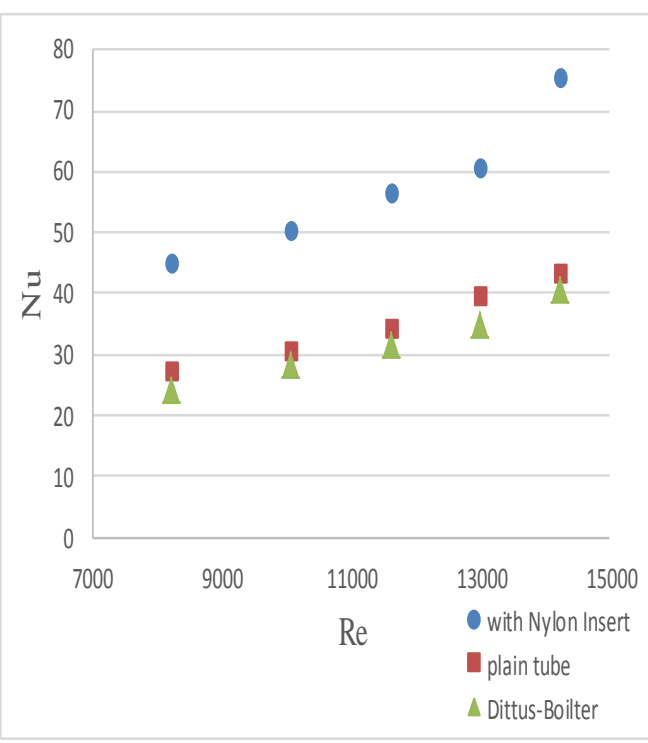

a) For heater input $\mathrm{P}=50 \mathrm{~W}$

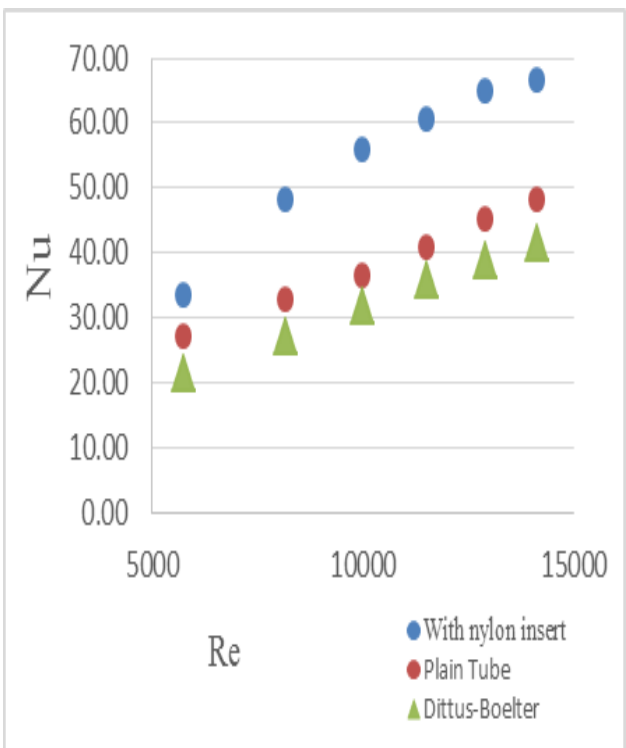

b) For heater input $\mathrm{P}=100 \mathrm{~W}$

Fig.3 Comparison of Nusselt number with and without insert

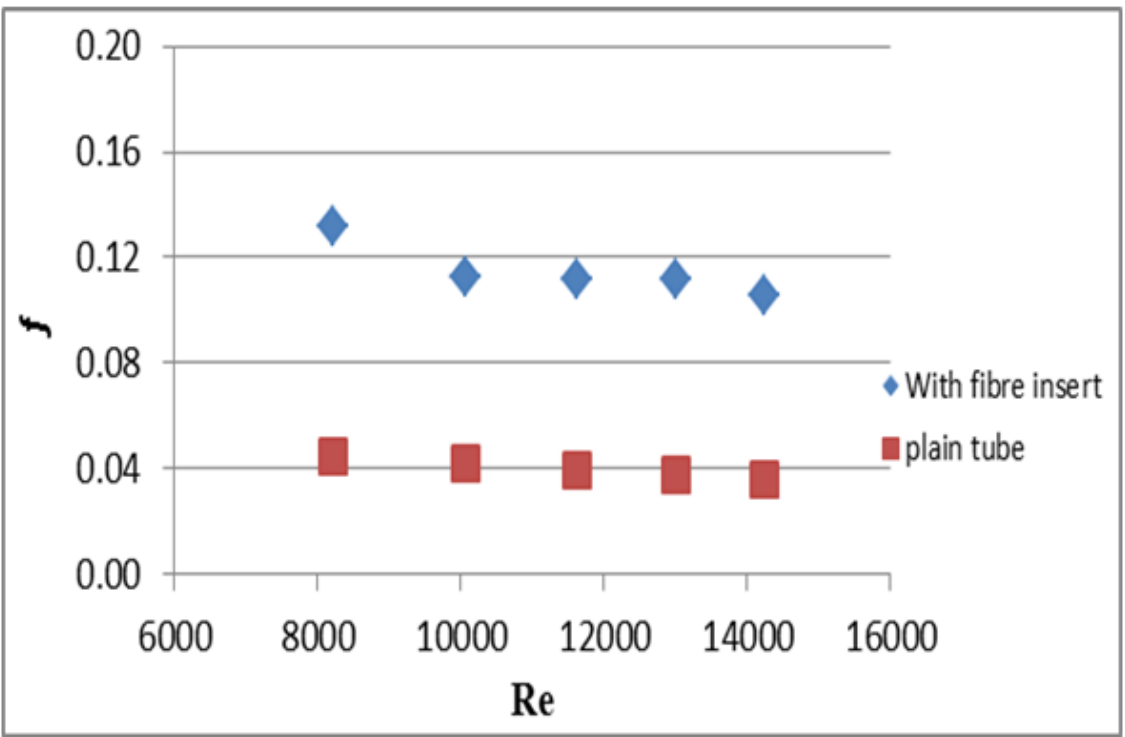

Fig.4 Variation of friction factor with Reynolds number

\section{Conclusion}

Experimental investigations were performed to investigate the friction factor and heat transfer characteristics in an externally heated horizontal tube fitted with different types of inserts. For plain tube, the experimental data is in good agreement with correlations value i.e. Dittus-Boelter and petukhov correlation. Experimental data of the present work is reasonably agreed within $10 \%$ for Nusselt number from Dittus Boelter correlation and $13 \%$ for friction factor from Blasius correlation. For non-metallic flow divider type inserts, the Nusselt number is $170 \%$ of that for plain tube. OER is above unity and maximum value obtained is 1.338 .Enhancement efficiency ranges from 1.5 to 2 which show that the thermal performance is improved. 


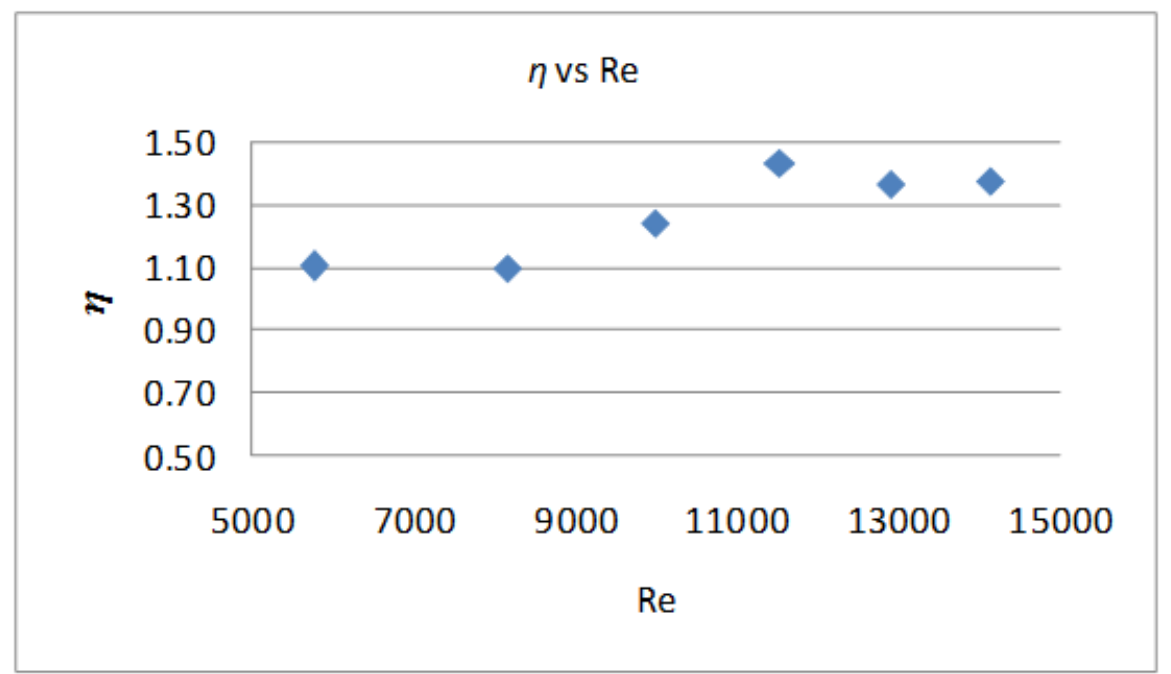

Fig.5.Variation of Overall Enhancement ratio for different Reynolds number

\section{REFERENCES}

[1]. A Dewan, P Mahanta, K Sumithra Raju and P Suresh Kumar ,Review of passive heat transfer augmentation techniques" Proceedings of the Institution of Mechanical Engineers, Part A: Journal of Power and Energy, 2004.

[2]. Hasenpur, M.farhadi and k.sedighi, A Review study on twisted tape inserts on turbulent flow heat exchanger: The overall enhancement ratio criteria, International communication in Heat and Mass Transfer. 55 ,2014,53-62.

[3]. Chou Xin Tan, Wai Loon Mah, Yew Mun Hung and Boon Thong Tan, On the role of inserts in forced convection heat transfer augmentation, International Communication in Heat and Mass Transfer.39,2012,1138-1145.

[4]. S.Rainieri, F.Bozzoli, G.Pagliarini, Experimental investigation on the convective heat transfer in straight and coiled corrugated tubes for highly viscous fluid : Preliminary results, International Journal of Heat and Mass Transfer 55 (2012) 498-504.

[5]. Smith Eiamsa ard and Pongjet Promvonge, Performance assessment in heat exchanger tube with alternate clockwise and counter-clockwise twisted-tape inserts, International Journal of Heat and Mass Transfer 53,2010, 1364-1372.

[6]. Atipoang Nuntaphan, Sanparwat Vithayasai , Nat Vorayos, Nattanee Vorayos, Tanongkiat Kiatsiriroat,Use of oscillating heat pipe technique as extended surface in wire-on-tube heat exchanger for heat transfer enhancement, International Journal of Heat and Mass Transfer 37 ,2010, 287-292.

[7]. A. Rabienataj Darzi, Mousa Farhadi ,Kurosh Sedighi, Shahriar Aallahyari, Mojtaba Aghajani Delavar, Turbulent heat transfer of Al2O3-water nanofluid inside helically corrugated tubes:Numerical study, International Journal of Heat and Mass Transfer 41 ,2013, 68-75.

[8]. Bargles, A. E. Techniques to augment heat transfer. Hand-book of Heat Transfer Applications. Ed. W.M. Rosenhow 1985 Ch. 3 McGraw-Hill New York. 